\title{
DISTORTIONAL INFLUENCE OF PALLET RACK UPRIGHTS SUBJECT TO COMBINED COMPRESSION AND BENDING
}

\author{
J. Bonada, M.M. Pastor, F. Roure, M. Casafont \\ Strength of Materials and Structural Engineering Department ETSEIB UPC \\ jordi.bonada@upc.edu,m.magdalena.pastor@upc.edu,francesc.roure@upc.edu,miquel.casafont@upc.edu
}

Keywords: Rack uprights, combined compression and bending, FE analysis, experimental testing.

\begin{abstract}
A pallet rack is a structure in which the beams and uprights are cold-formed steel sections. The beam-upright connections are normally clipped in order to select the beam levels required and for ease of assembly. For this reason, the uprights contain holes and perforations distributed along their length. The complexity of these components, with local, distortional and torsional/flexural buckling behaviour, represents a challenge in structural design. The loads acting on the structure are induced by the weight of pallets to be stored, and transmitted to the uprights by the semi-rigid connection system. Therefore, the uprights are thin-walled singly symmetrical perforated open crosssections bearing axial load and bending moment simultaneously. The main objective of this paper is to analyse the influence of the bending moment on the load bearing capacity of rack uprights subject to axial load together with bending moment. Bending is induced by means of axial forces eccentrically applied. The influence of bending on the strength capacity of rack uprights is analysed through finite element analysis, where residual stresses and strength enhancement induced during cold forming of sections are also considered. Experimental tests have been performed reproducing the load conditions in order to validate the FEA results. The ultimate load has also been calculated according to European standards and compared to experimental results.
\end{abstract}

\section{INTRODUCTION}

The main components of a steel storage pallet are the uprights, the pallet beams and the diagonals. The uprights are usually subjected to axial load and bending moment. The loads carried by the pallet beams are transmitted to the uprights through semi-rigid connections. When the loads are symmetrically distributed, at both sides of an upright, then it is working in pure compression. Whereas when the loading scheme is asymmetric, then the upright is subjected to compression and bending. The case of pure axial load is extremely rare in rack design practice and it is generally associated with the verification of lacings. With reference to the uprights, in addition to the contribution due to axial load, it is of fundamental importance to take into account also the presence of bending moments along the principal axes of the cross-section [1].

Extensive research has been focused on members loaded under pure compression; among these, [2-3] that are devoted to experimental testing of compressed members. Three methods (analytical, experimental and FEA) to estimate the effective area and the position of the centre of gravity for perforated sections are presented in [2]. Experimental deformations were measured on specimen lengths prone to distortional buckling failure in order to analyse the interaction between distortional and global buckling modes [3].

However, little research has been done to date about the behaviour of uprights subjected to combined compression and bending. Miller and Pekoz [4] investigated the behaviour of coldformed steel lipped-channel columns with rectangular perforation patterns eccentrically loaded, and code predictions were compared with empirical responses. The results from an 
experimental investigation and a finite element analysis of cold-formed channel columns with inclined simple edge stiffeners subjected to eccentric loads presented by Zhang et al. in [5], show that loading position affects the load carrying capacity and failure mode of specimens. Mohri et al. [6] investigated bi-symmetric cross-sections under combined bending and axial forces and compared a non-linear model for the stability analysis to non-linear finite element results. An experimental campaign [7] is conducted on the behaviour of cold-formed steel lipped-channel beam-columns under bi-axial bending and compression to characterize the failure modes and the member capacity, and the results are used to verify the reliability of code predictions about the strength of beam-columns.

Concerning racks, Davies et al. [8] compared both GBT (with treatment of perforations) and FEA for predicting the failure load of perforated cold-formed steel sections subject to axial load and bending with test results. Crisan et al. [9] carried out a testing program including bending about minor axis of single uprights with web in compression and tension, according to Annex A.2.9 [10]. Bernuzzi and Simoncelli [11] analysed the interaction between axial loads and bending moments in rack uprights, therefore three European design approaches were compared to evaluate the beam-column capacity.

The purpose of this paper is to investigate eccentrically compressed rack members in order to reproduce compression and uniform bending load case and analyse the influence of distortional buckling in the upright. Uniform axial bending and compression were reproduced by means of a loading set-up specifically designed to apply eccentric axial loads. Experimental tests are performed on $700 \mathrm{~mm}$ upright length with eccentricities defined on the non-symmetrical axis of the cross-section. Two different methodologies to obtain the load carrying capacity of the upright by FEA are presented and compared to experimental results. Finally, the failure load is also obtained through the European Standards in order to analyse its agreement with experimental measurements.

\section{EXPERIMENTAL TESTS}

\subsection{Analysed cross-section and material testing}

The analysed rack upright (steel grade S355) is shown in Figure 1. It is a commercial open cold-formed steel section, whose main dimensions are: web width of $80 \mathrm{~mm}$, flange height of $69 \mathrm{~mm}, 1.8 \mathrm{~mm}$ of thickness and $4.4 \mathrm{~mm}$ of corner radii. The holes are located at the middle position of flange parts.

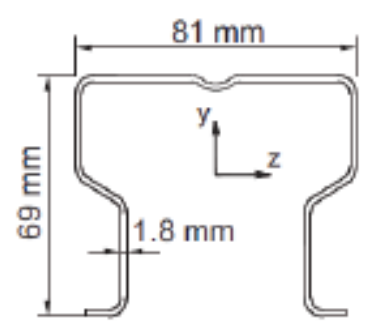

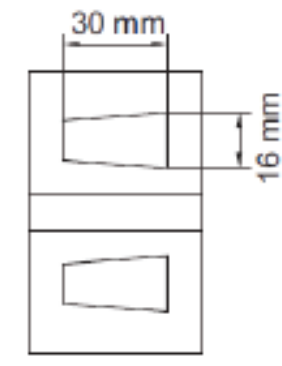

Web perforations

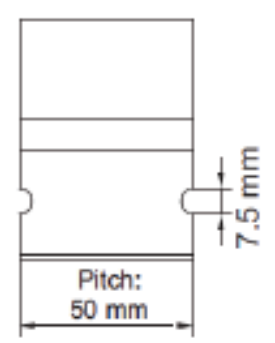

Flange perforations

Figure 1: Main dimensions of the analysed rack upright. 
Most of rack sections are manufactured by cold-roll forming. As a consequence, the mechanical properties of the material may be different from the virgin sheet coil. Therefore, several tensile coupons were cut out from flat and corner areas of the upright in order to determinate their stress-strain behaviour. Flat coupons were cut out from the only part of the flange without any perforation. All corners radii of the cross-section have the same value, thus the enhancement of its mechanical properties was evaluate though coupons obtained from corner area shown in Figure 2.

Table 1 shows the values of yield and ultimate strength obtained from the tensile tests following the recommendations of EN100002-1 European Standard. It can be observed that the yield and ultimate strength in corner areas are a $17.5 \%$ and $7.7 \%$ higher than in flat areas due to strain hardening, respectively. Moreover, the engineering stress-strain curves for all tensile coupons are plotted in Figure 3. It can be observed the enhancement of the yield stress and ultimate stress of corner coupons due to strain hardening. On the other hand the ductility has decreased.

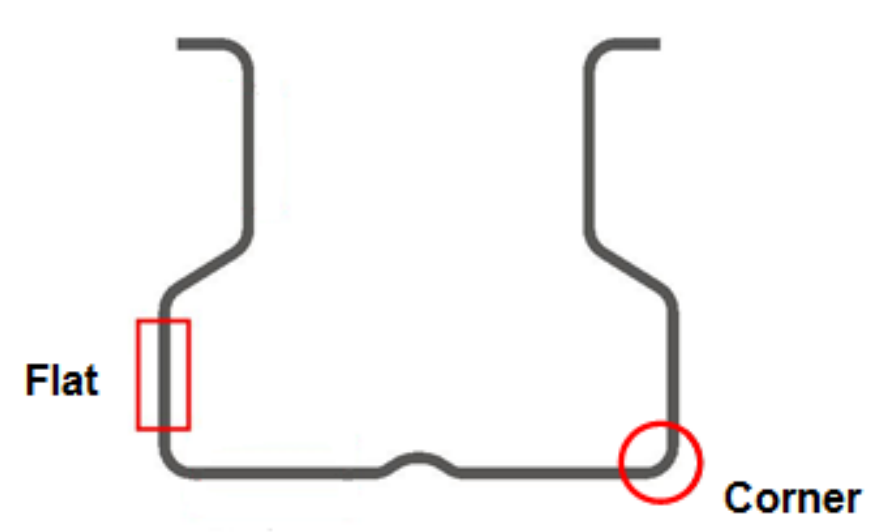

Figure 2: Flat and corner zones were tensile coupons were cut out

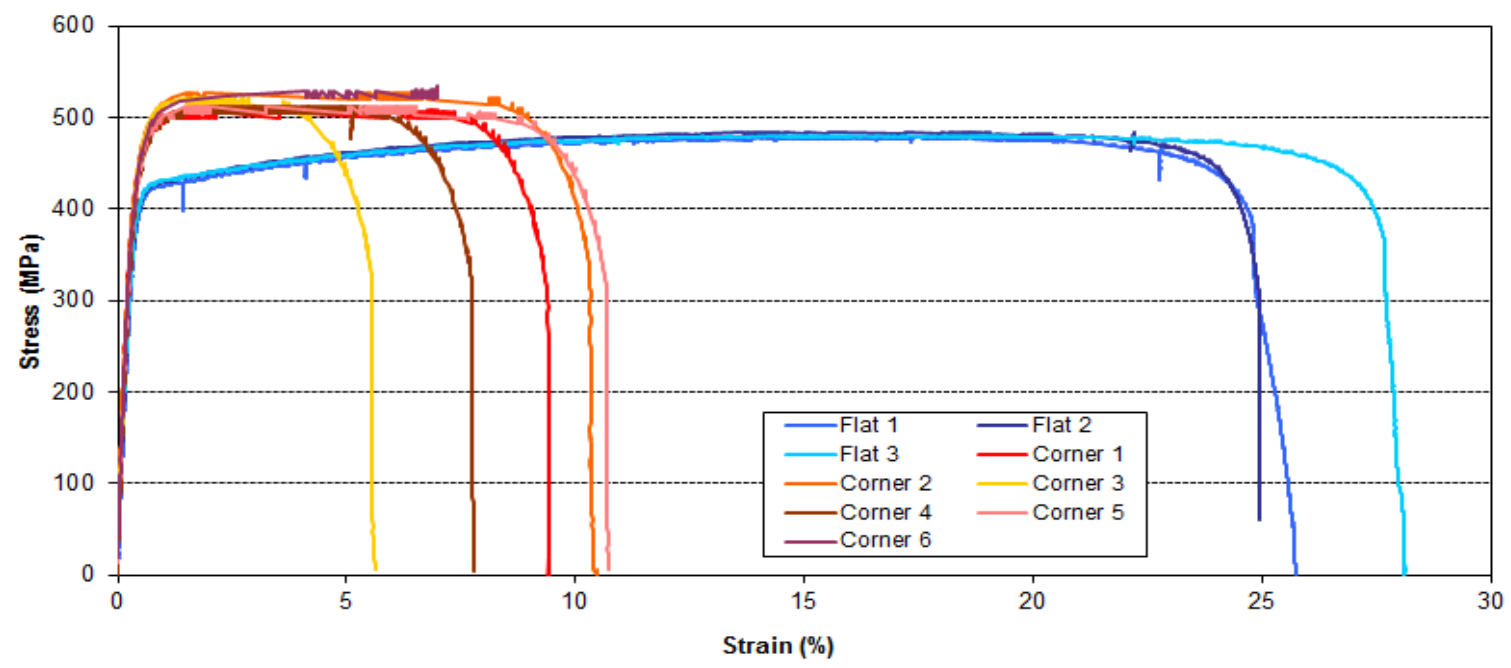




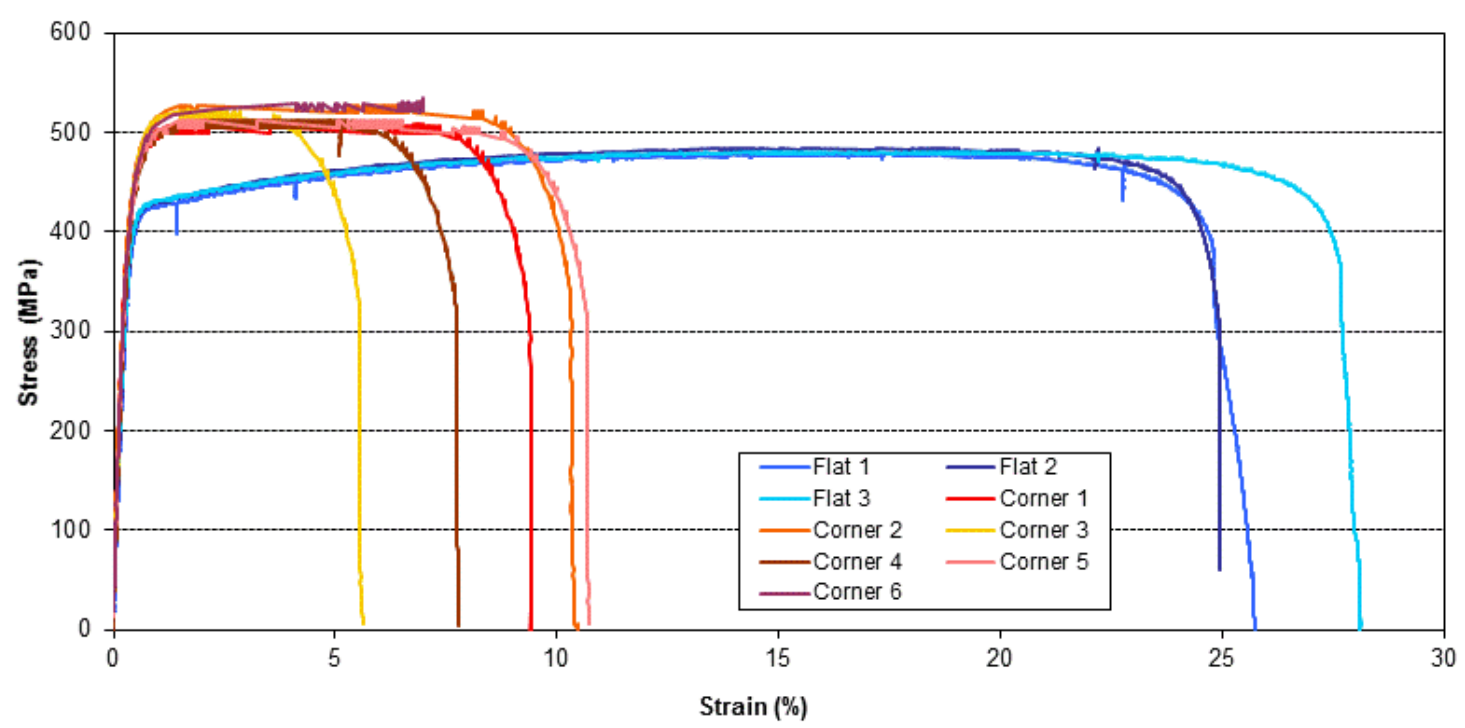

Figure 3: Engineering stress-strain curve for the tensile tests

\subsection{Experimental set up}

Several experimental tests have been done to determine the load carrying capacity of the rack upright subject to a combined compression and bending. Bending is induced by means of axial forces eccentrically applied. At each end of the rack upright a plate made of $30 \mathrm{~mm}$ thick steel is used to restrain the distortion and warping displacement of the section (Figure 4). In order to introduce the eccentric axial force, a second steel plate of $15 \mathrm{~mm}$ of thickness is fixed to the first one through a system of slotted holes and bolts, which allows the lateral displacement ( $\mathrm{Z}$ direction) of the longitudinal upright axis from the application point of the axial force (Figure 5). In addition, the whole sample has the flexural deformation modes pinned at both ends by means of two steel balls that fix the load application point (Figure 6). Finally, a special device avoids the rotation around the longitudinal axis of the specimen by means of guides and cylinders (Figure 6-7). 


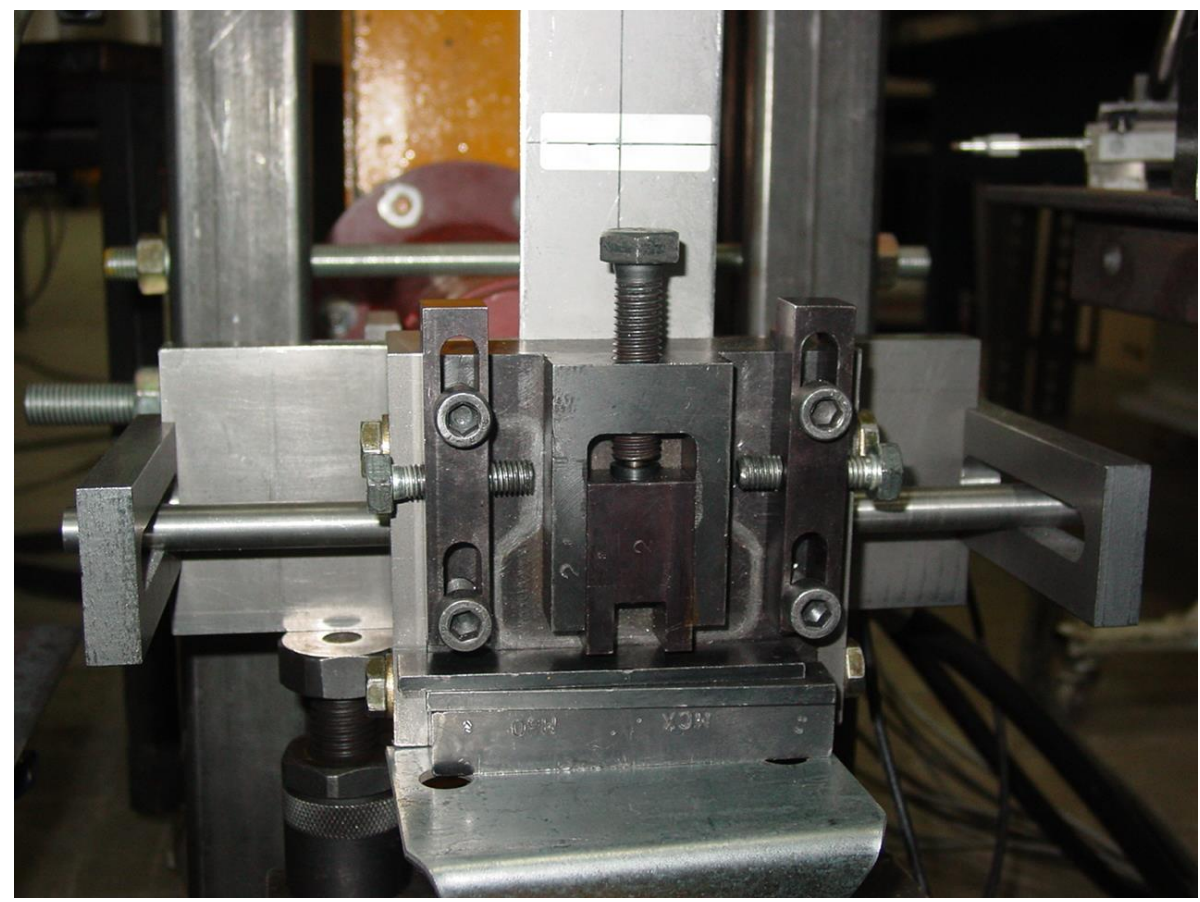

Figure 4: Plate 1 restrains sectional and warping displacements while the whole sample is pinned at both ends and the rotation is prevented.

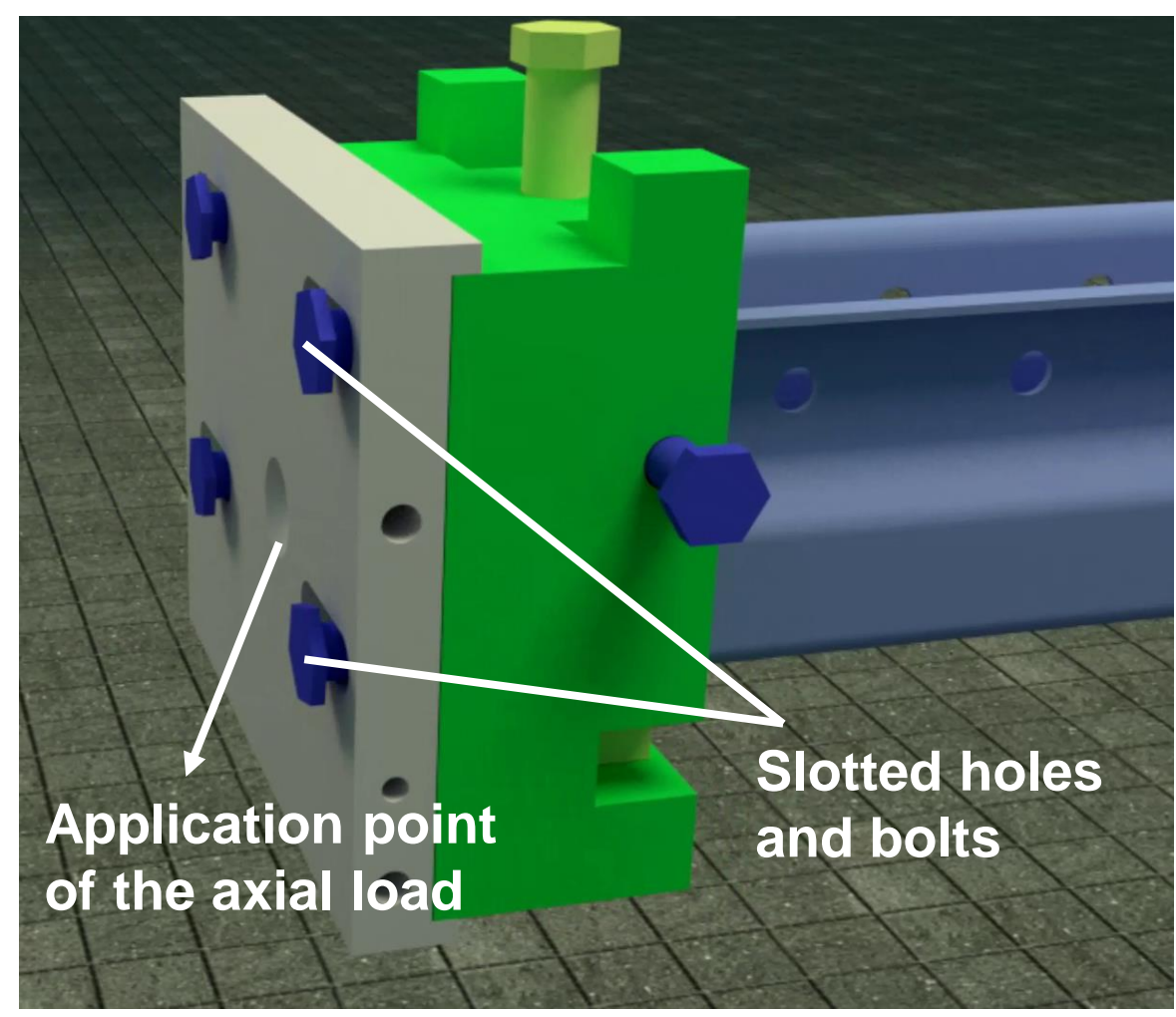

Figure 5: Plate 2 (white) is fixed to plate 1 (green) through a system of slotted holes, which allows the lateral movement of the upright longitudinal axis, enabling the application of an eccentrically axial load. 


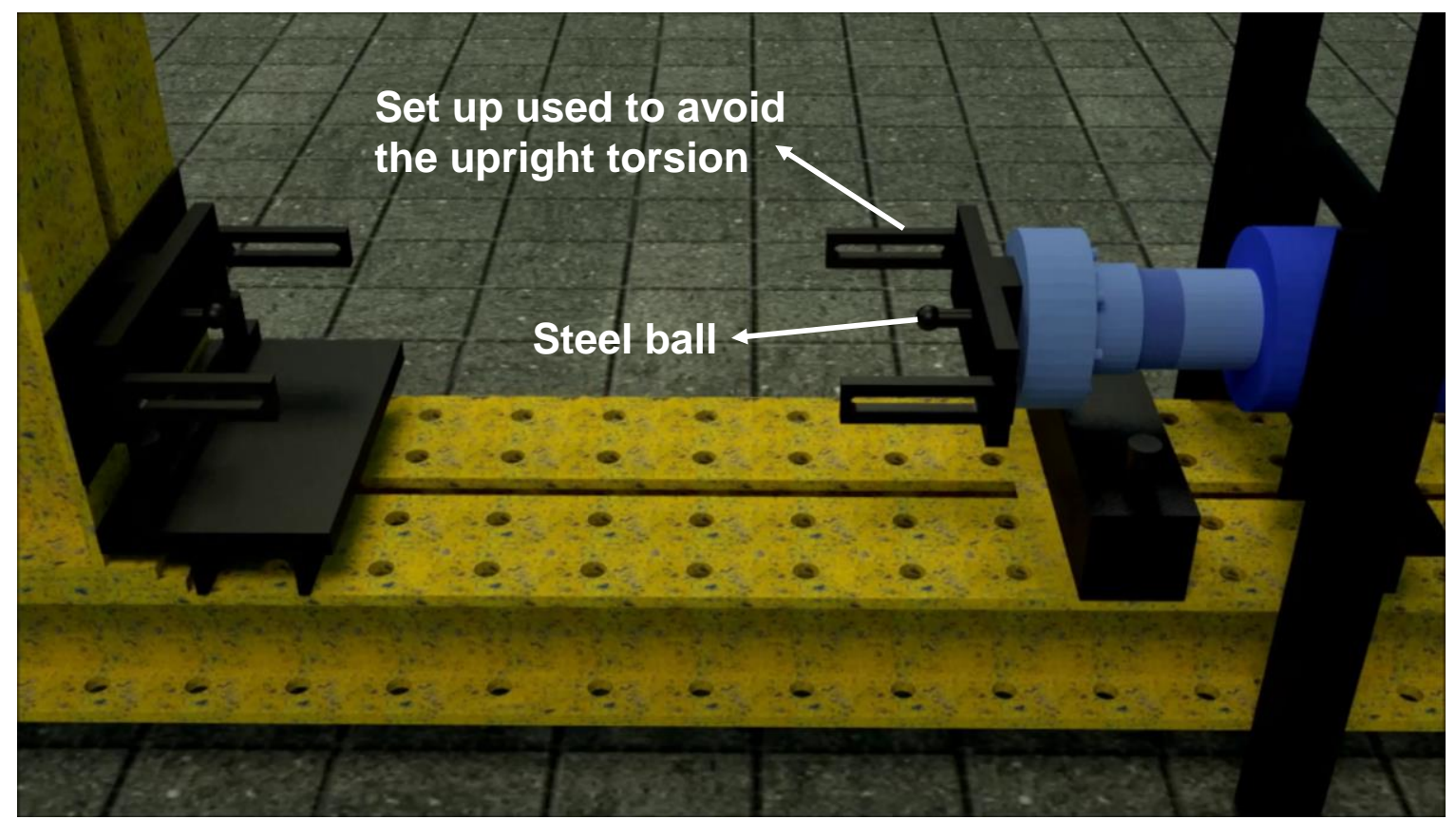

Figure 6: Set up used to apply the axial force by a hydraulic jack. The steel balls fix the load application point.

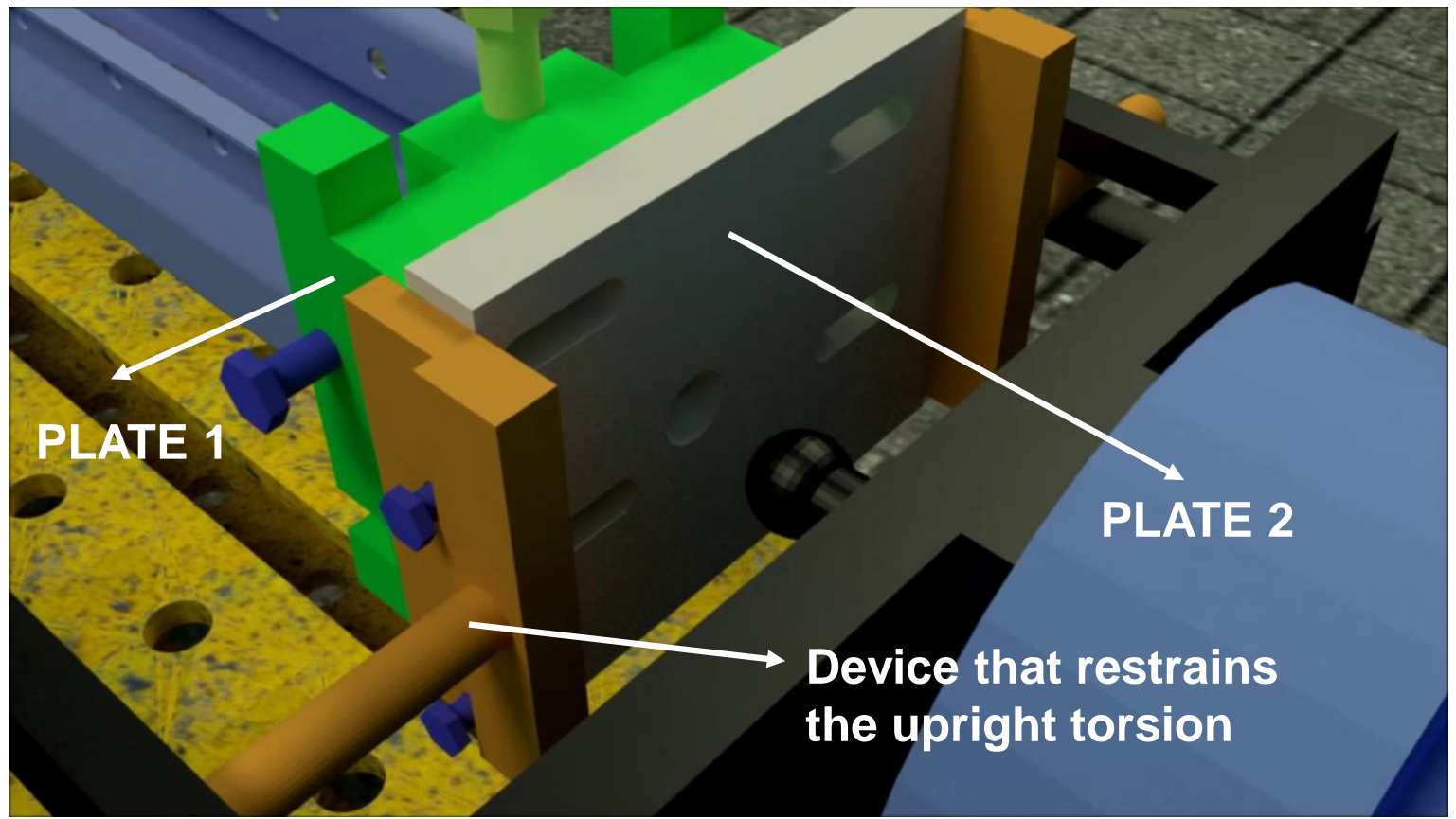

Figure 7: Detail of the steel ball used to apply the axial force and the special device (guides and cylinders) used to restrain the upright torsion at both ends while the flexural modes remains pinned. 
The axial load is applied by means of a hydraulic jack, with a load speed of $150 \mathrm{~N} / \mathrm{s}$ and measured by a force transducer. The shortening of the upright is also measured by four displacement transducers (Figure 8).

Columns of steel storage rack structures are usually subjected to a compression load and a bending moment simultaneously due to the semi-rigid behaviour of the column to beam connection. On these columns, the bending moment can represent until a $20 \%$ or $30 \%$ of their load carrying capacity in a typical pallet rack structure. First of all, the effective centre of gravity (cdg) is experimentally obtained on a short column according to EN15512. Secondly, four different eccentricities have been tested in order to reach this bending moment level for the analysed section: 0, 5, 15 and $20 \mathrm{~mm}$ (Figure 9-10). The study is focused on a dominant distortional buckling length (700 mm upright length).

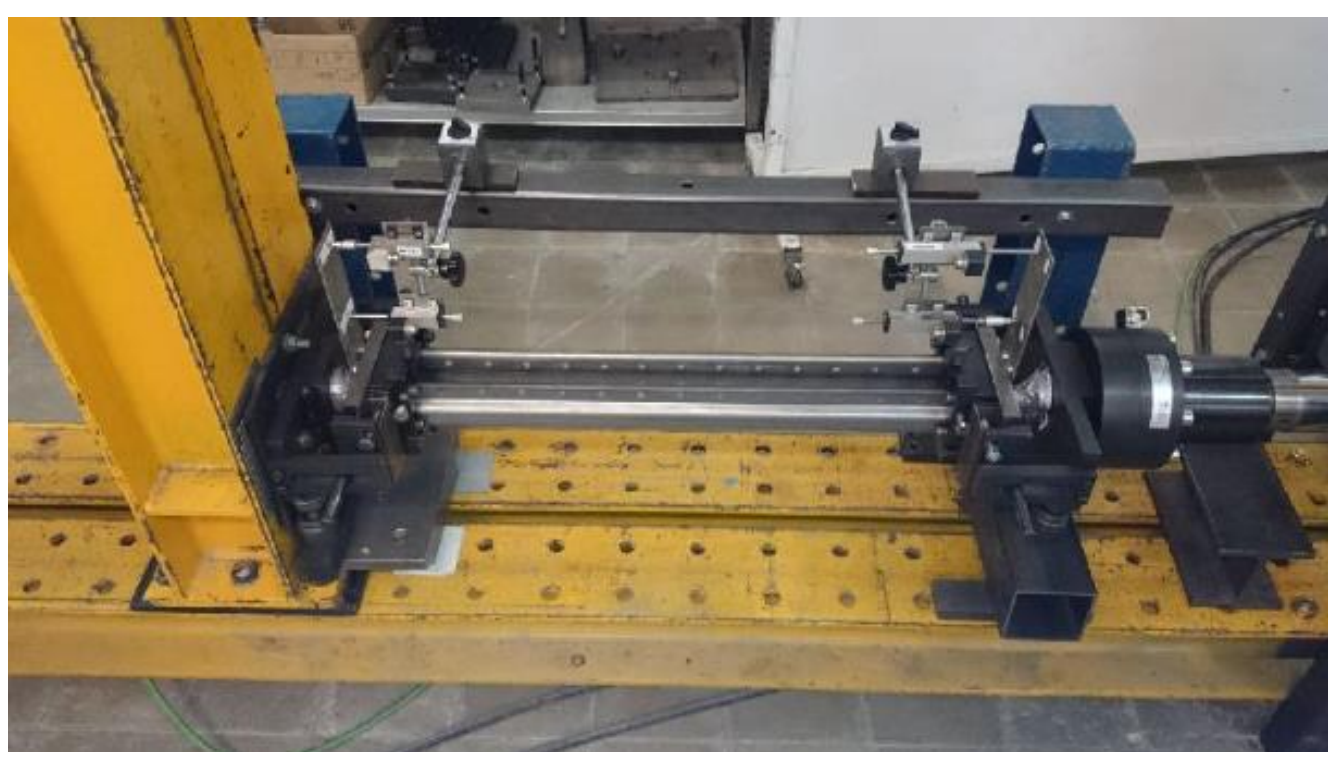

Figure 8: Set up of the displacement transducers used to obtain the axial displacement of the rack upright
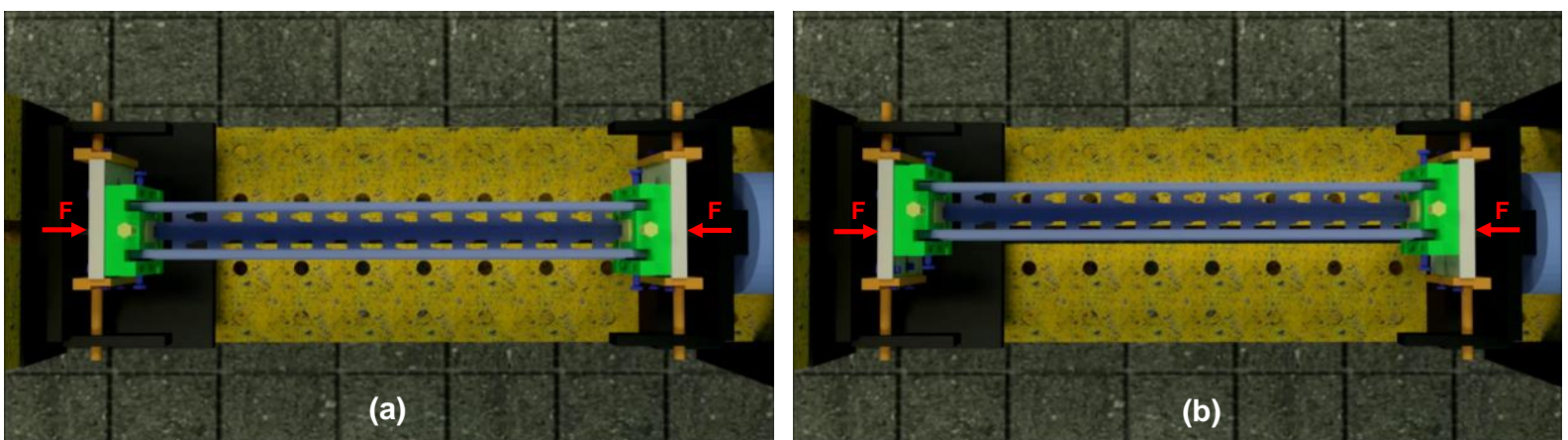

Figure 9: (a) Position of the upright for a null eccentricity of the axial load. (b) Position of the upright for the maximum eccentricity of the axial load allowed by the set up. Note than lateral displacement of the upright and plates 1 (green plates) is allowed by the system of slotted holes and bolts of plates 2 (white plates). 


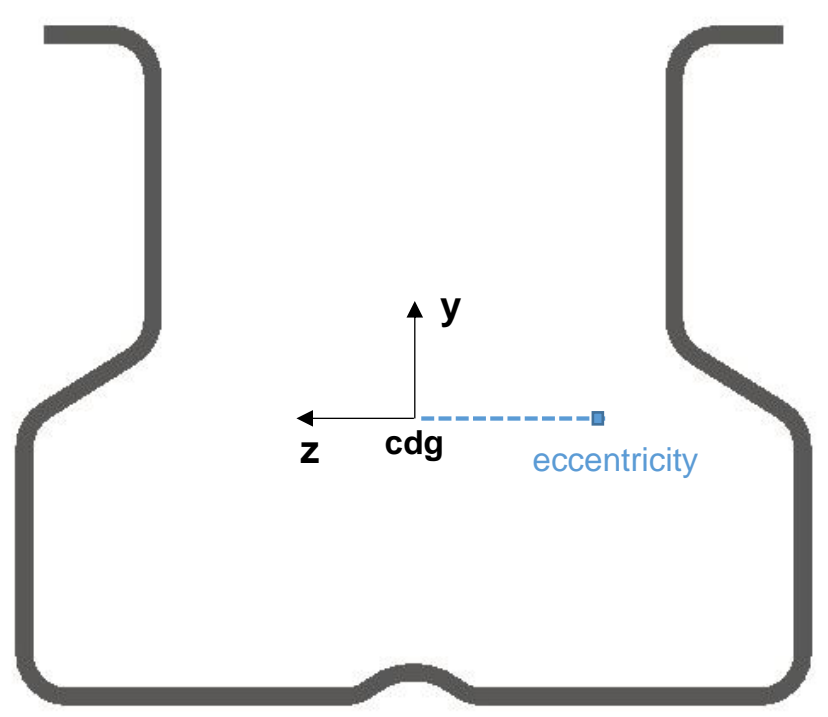

Figure 10: Scheme of the cdg (located at $29.5 \mathrm{~mm}$ from the web) and the applied eccentricity ( $\mathrm{z}$ direction)

\subsection{Tests results}

Table 2 and Figure 6 show the values of the experimental tests and the failures modes obtained, respectively. The symmetric distortional (SD) buckling mode is the most dominant for the rack upright without any eccentricity. Furthermore, the more the eccentricity increases, the less the symmetric distortional buckling mode is dominant. For the largest eccentricity, only one flange is clearly deformed while the other shows a slightly displacement.

Table 2 - Ultimate load obtained by the experimental tests

\begin{tabular}{|c|c|c|c|c|}
\hline $\begin{array}{l}\text { Eccentricit } \\
\mathbf{y}(\mathbf{m m})\end{array}$ & Sample & Ultimate Load (N) & $\begin{array}{l}\text { Mean of ultimate } \\
\operatorname{load}(\mathbf{N})\end{array}$ & $\begin{array}{l}\text { Mean of ultimate } \\
\text { Bending moment } \\
(\mathbf{N} \cdot \mathbf{m})\end{array}$ \\
\hline \multirow{3}{*}{0} & 1 & 116000 & \multirow{3}{*}{117590} & \multirow[t]{3}{*}{ 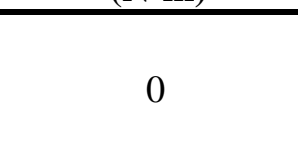 } \\
\hline & 2 & 122000 & & \\
\hline & 3 & 114770 & & \\
\hline \multirow{3}{*}{5} & 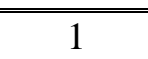 & 101440 & \multirow{3}{*}{102257} & \multirow{3}{*}{511.3} \\
\hline & 2 & 99390 & & \\
\hline & 3 & 105940 & & \\
\hline \multirow{3}{*}{10} & 1 & 87660 & \multirow{3}{*}{89493} & \multirow{3}{*}{894.9} \\
\hline & 2 & 89200 & & \\
\hline & 3 & 91620 & & \\
\hline \multirow{3}{*}{15} & 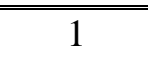 & 78100 & \multirow{3}{*}{76743} & \multirow{3}{*}{1151.1} \\
\hline & 2 & 74400 & & \\
\hline & 3 & 77730 & & \\
\hline \multirow{3}{*}{20} & 1 & 70930 & \multirow{3}{*}{71673} & \multirow{3}{*}{1433.5} \\
\hline & 2 & 71530 & & \\
\hline & 3 & 72560 & & \\
\hline
\end{tabular}




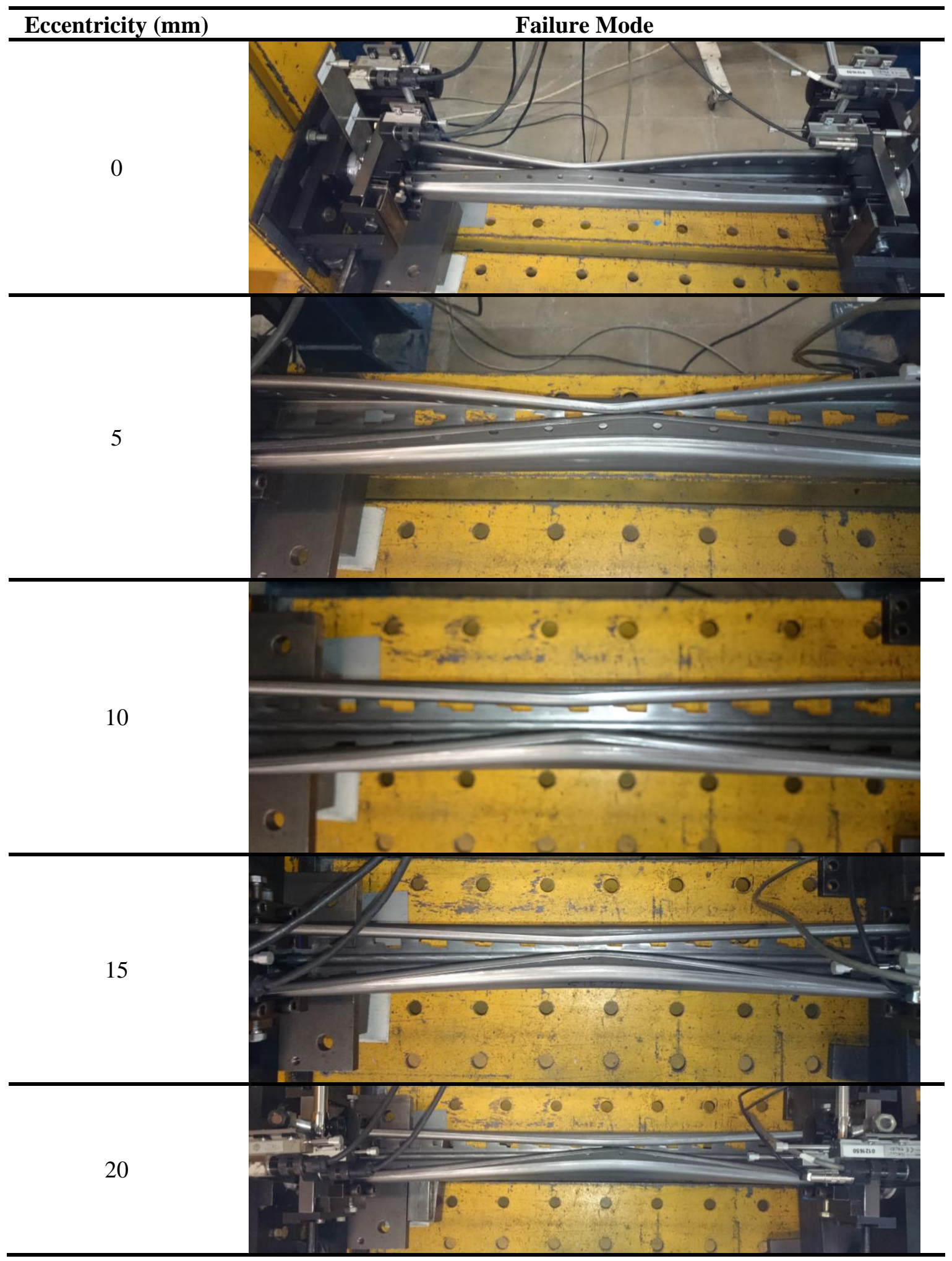

Figure 11: Failure modes of the experimental tests. 


\section{FINITE ELEMET ANALYSIS}

ANSYS [12] code has been used in order to carry out the finite element analysis of the specimens.

The connection between the end section of the upright and the plates is done by coupling each displacement degree of freedom of the end upright node with the node located at the same position of the load plate. Thus, the distortion of the end section is restrained. At one load plate all degrees of freedom are fixed at the position where the upright is loaded, whereas on the other plate only the in-plane displacements are blocked while an increasing displacement in the axial direction is applied. Finally, two additional displacement restraints are added at each plate to avoid its rotation about the longitudinal axis.

A geometrical and material nonlinear analysis is done to obtain the ultimate load of the rack upright. The iterative method of Newton-Rhapson has been used to solve it.

\subsection{Simulation without residual stresses}

When a nonlinear buckling analysis of a rack column under a pure compression load is done, an initial geometric imperfection is introduced to obtain accurate results [13]. On the other hand, if the compression load is eccentrically applied it can be no longer necessary to introduce any imperfection to generate a flexural collapse of the upright. However, it might be necessary if the distortional buckling is still relevant in the failure mode of the upright. Therefore, for each eccentricity, two simulations have been done, one with a distortional geometrical imperfection and another without any geometrical imperfection. The influence of the distortional geometrical imperfection can be studied by means of these analyses. The geometrical imperfection introduced as initial perturbation is a symmetrical distortional buckling shape obtained by a linear buckling analysis. The magnitude of the imperfection introduced corresponds to $1.38 \mathrm{~mm}$ (flange width/50) and it is inspired by EN1993-1-5. This magnitude is higher than experimental measurements done by the authors of similar sections (0.6-0.85 $\mathrm{mm}$ approximately). However, the aim of this geometrical imperfection introduced as initial state in FEA is to consider the influence of residual stresses, strength enhancement and real geometrical imperfections. An exhaustive study about the influence of the amplitude imperfections on the load carrying capacity of a rack upright can be found in [13].

The created model uses 8-node brick elements (Solid 185) and 4-node shell elements (Shell 181) for the plates and the upright, respectively. The behaviour of the material has been defined as isotropic, with a stress-strain relation that follow the experimental curve obtained from the flat coupons. For these simulations, the strength enhancement of corner areas and the residual stress distribution has not been taken into account.

\subsection{Simulation with residual stresses and strength enhancement of corner areas}

The residual stresses of the rack section are obtained via a geometric and material nonlinear finite element analysis of the cold roll-forming process done in COPRA RF software. In order to simulate the manufacturing process only a half of the steel sheet is considered (Figure 12) due to the symmetry of the roll forming line. Once COPRA simulation is done, only one residual elastic and plastic strain pattern is defined for a virtual cross-section without any perforation. The residual longitudinal stresses obtained due to the manufacturing process can be seen in Figure 13. More details about COPRA simulation as well as the characteristics and methodology to define this pattern are explained in [15]. 
The finite element analysis to predict the load carrying capacity of the upright is done in ANSYS software. The residual stresses due to the manufacturing process are considered by introducing the residual strain pattern, previously defined, as initial state in ANSYS analysis. In order to introduce all residual strain component's due to the roll forming process the upright has been meshed with a 20-node brick element (SOLID 186). Notice than the finite element used when the residual stresses and the strain hardening are considered is different. A 20-node brick element is used instead of 4-node shell element due to the impossibility to correctly reproduce the cold work effects (residual stresses) through the thickness direction with a shell element. In order to introduce the enhancement of the mechanical properties of corner areas two different materials have been use to mesh the upright. The true stress-strain relationship (Figure 14) for both materials (flat and corner regions) used in the finite element model follows the experimental curves obtained in Section 2.1. It is also possible to obtain the strength enhancement of corner areas through the finite element analysis of the roll-forming process done in COPRA analysing the equivalent plastic strain or curved regions and introducing the residual equivalent plastic strain in ANSYS modes as initial state with similar results [15].

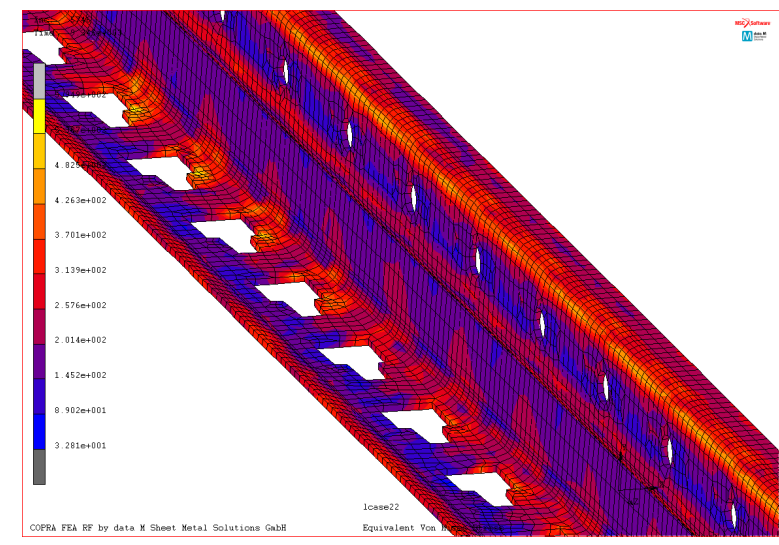

(a)

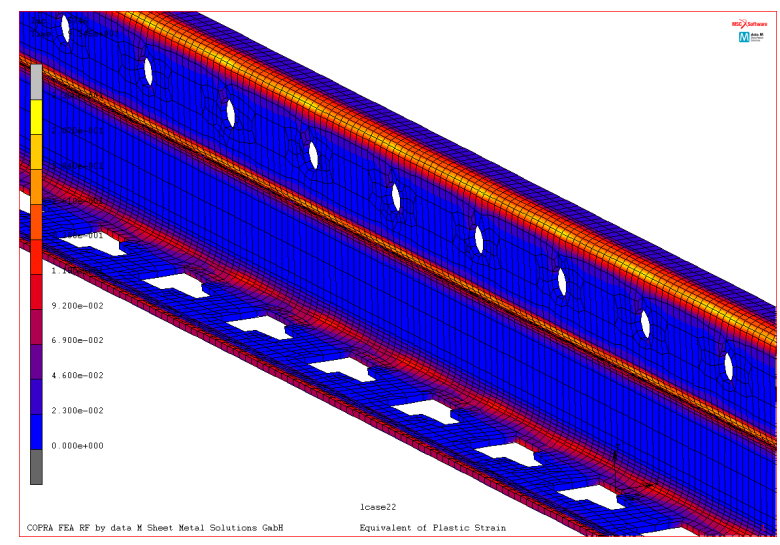

(b)

Figure 12: Equivalent Von Mises Stress (a) and equivalent plastic strain (b) of the rack section obtained by the finite element analysis of the roll forming process done in COPRA.

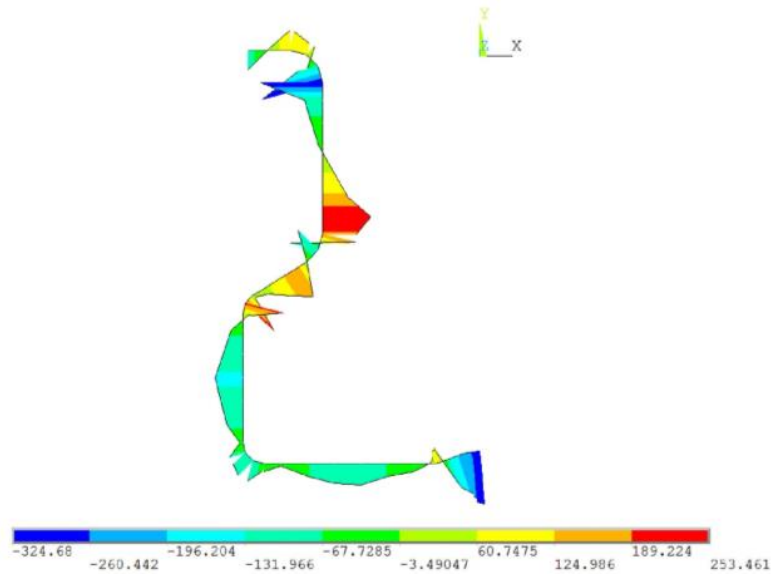

(a)

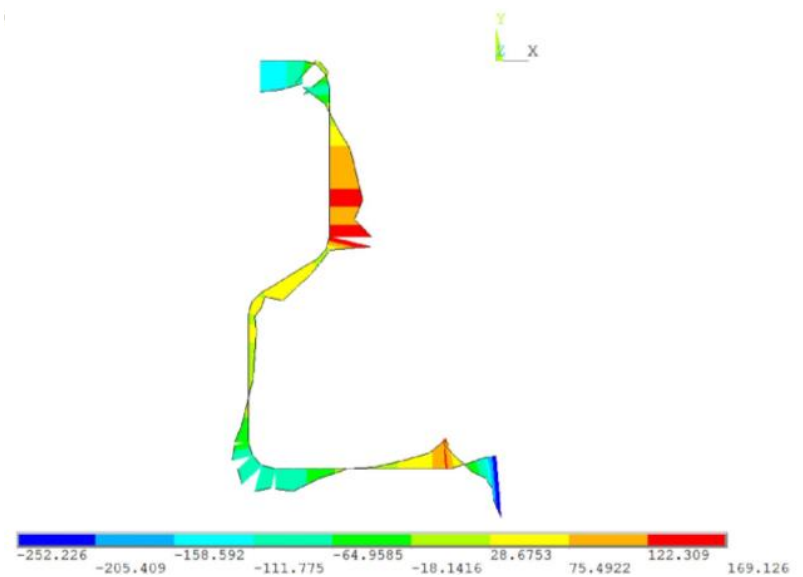

(b)

Figure 13: Longitudinal residual stress distribution obtained due to the finite element analysis of the rollforming process in the inner face (a) and the middle of the thickness (b) 


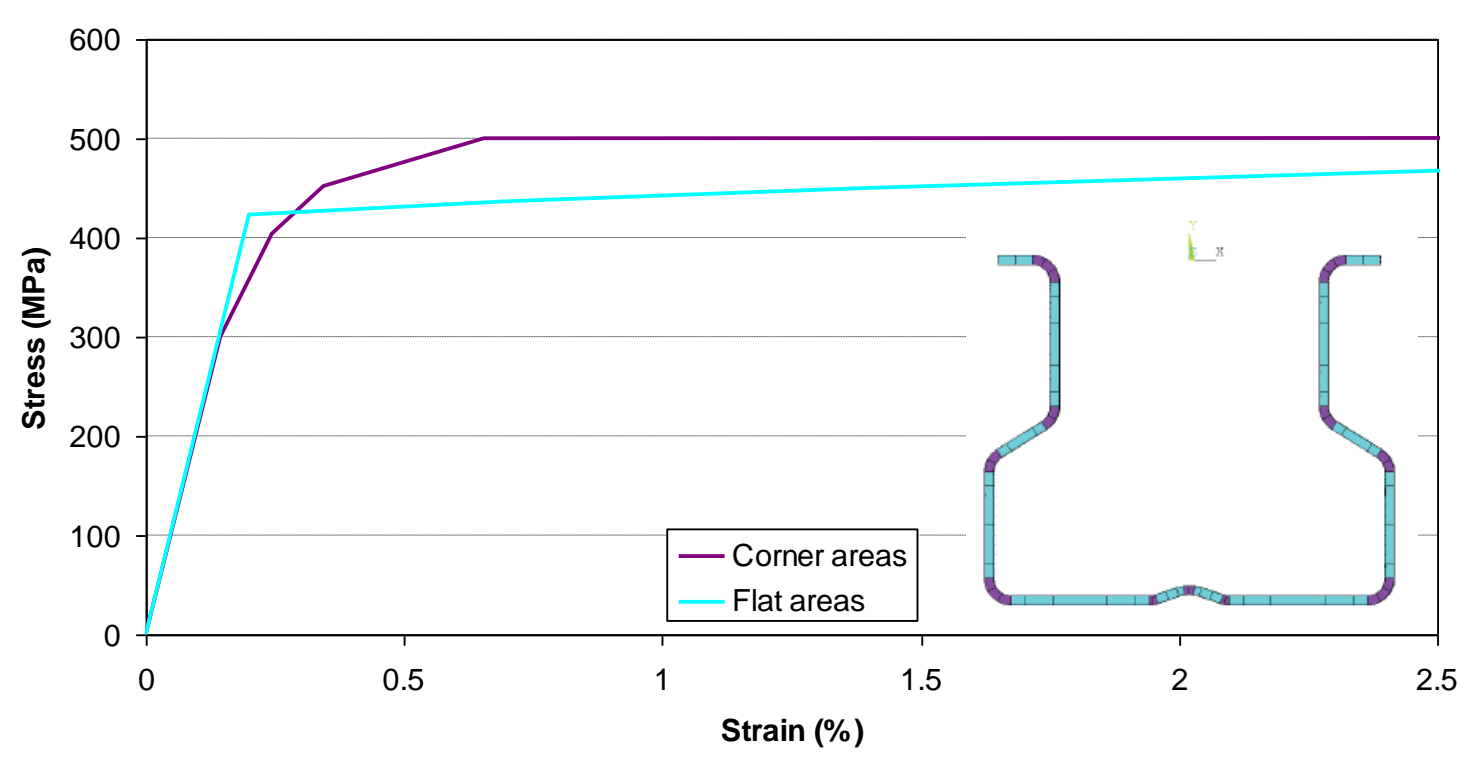

Figure 14: Numerical true stress-strain relationships for flat and corner areas

The residual elastic and plastic strain (not the equivalent plastic strain) pattern is extended on a geometrically perfect upright, without any initial geometrical imperfection (the imperfection generated in COPRA analysis has been neglected). The equilibrium of these residual strains produces a small deformation $(0.25 \mathrm{~mm})$ on the upright during the first step of the nonlinear analysis done in ANSYS. This deformation, similar to a symmetric distortional mode, is obtained as a consequence of introducing the same residual strain pattern along all the upright length.

The residual cold work effects obtained and used do not take into account the effect of punching, coiling and uncoiling the virgin sheet coil.

\section{DISCUSSION OF RESULTS}

\subsection{Comparison of ultimate loads and failure modes between experimental tests and numerical analysis}

Ultimate loads obtained through numerical analysis have been compared with the experimental ones (Figure 15). The results show that the load carrying capacity of the upright decreases as the eccentricity increases because of the influence of the bending moment. For a null eccentricity the axial load is applied at the effective centre of gravity according to EN15512. 


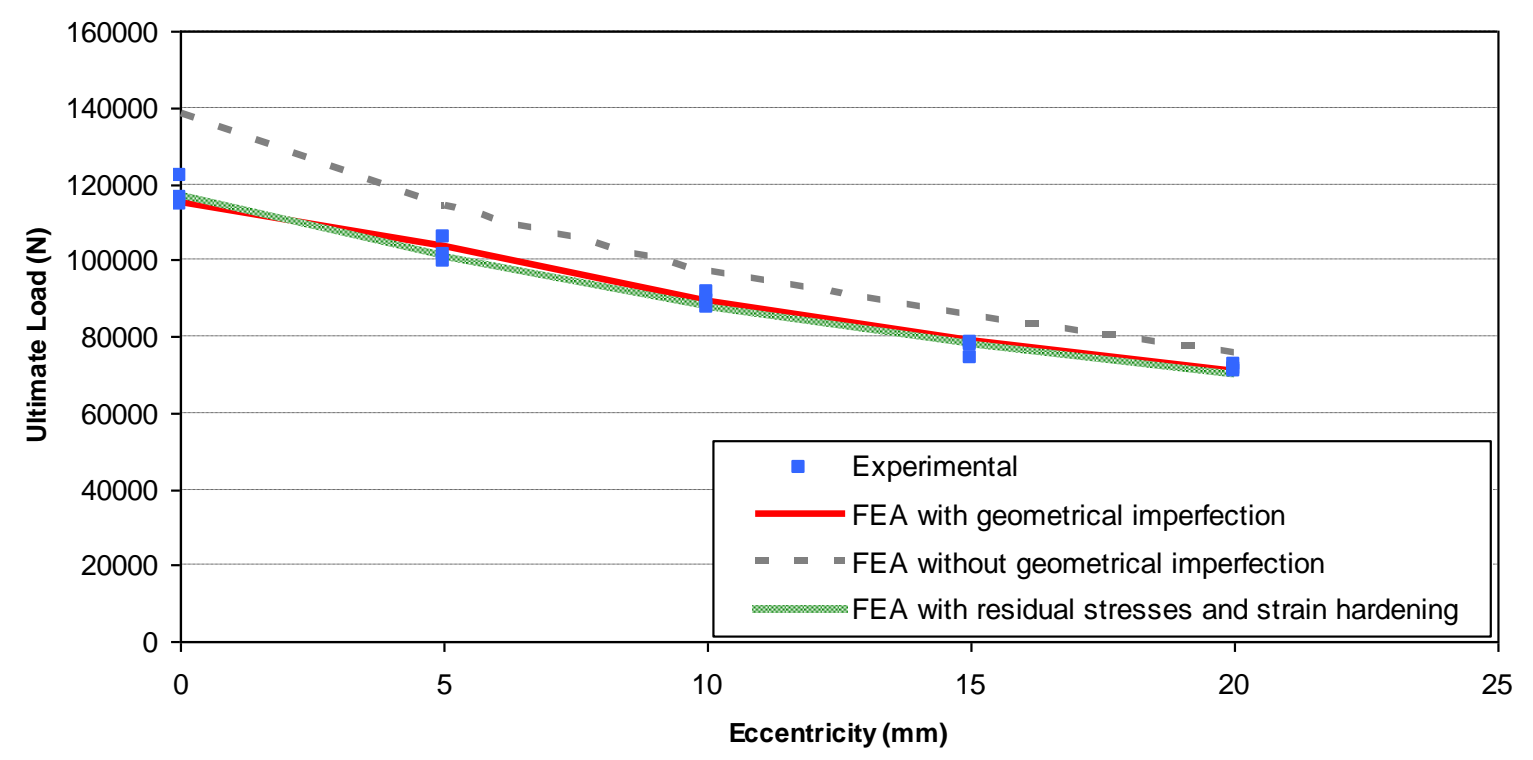

Figure 15: Influence of the eccentricity in the load carrying capacity of the upright.

It is necessary to introduce a distortional geometrical imperfection to achieve a good agreement between numerical and experimental ultimate loads if the residual stresses are not taken into account as it is shown in Figure 15 and Table 3. Moreover, although the load is eccentrically applied, the geometrical imperfection introduced in the nonlinear analysis has to have the same magnitude (flange width/50) used for a pure compression load to obtain accurate results.

A good prediction of the ultimate load is also obtained through the analysis with residual stresses and strength enhancement of corner areas. Furthermore, if this methodology is used no arbitrary geometrical imperfection is introduced as initial state for the nonlinear analysis. The balance of the residual strain pattern introduced as initial state produces a small deformation at the upright during the first step of the nonlinear analysis. This deformation only depends on the residual strain pattern obtained by the roll-forming process simulation. It is independent from the load case or boundary conditions of the analysis. Thus, the ultimate load does not depend on the magnitude and shape of any geometrical imperfection arbitrarily introduced. Consequently, all the issues related on the selection of a right type of a geometrical imperfection introduced as initial state can be avoided (Figure 16).

Table 3: Comparison of the results obtained. GI (analysis with geometrical imperfection), NGI (analysis without geometrical imperfection) and RS (analysis with residual stresses and strength enhancement).

\begin{tabular}{|c|c|c|c|c|c|c|}
\hline \multirow[b]{2}{*}{ Eccentricity (mm) } & \multicolumn{3}{|c|}{ FEA ultimate loads (N) } & \multicolumn{3}{|c|}{ FEA/EXP } \\
\hline & GI & NGI & RS & GI & NGI & $\mathbf{R S}$ \\
\hline 0 & 115283 & 138104 & 117476 & 0.98 & 1.17 & 1.00 \\
\hline 5 & 103827 & 113697 & 101480 & 1.02 & 1.11 & 0.99 \\
\hline 10 & 89360 & 96826 & 88132 & 1.00 & 1.08 & 0.98 \\
\hline 15 & 79113 & 85010 & 78064 & 1.03 & 1.11 & 1.02 \\
\hline \multirow[t]{3}{*}{20} & 70556 & 75505 & 70081 & 0.98 & 1.05 & 0.98 \\
\hline & & & Mean & 1.00 & 1.11 & 0.99 \\
\hline & & & St & 0.02 & 0.04 & 0.02 \\
\hline
\end{tabular}


On the other hand, the load carrying capacity and the failure mode obtained from FEA with geometrical imperfection for a pure compression load depends on the shape of the initial perturbation introduced [16]. In Table 4 and Figure 17 the ultimate loads and failure modes obtained by introducing a symmetric distortional (SD) and anti-symmetric distortional (AD) geometric imperfection are compared. The failure modes obtained are only different for a null eccentricity case; therefore, it only appears differences on the ultimate loads at this simulation.

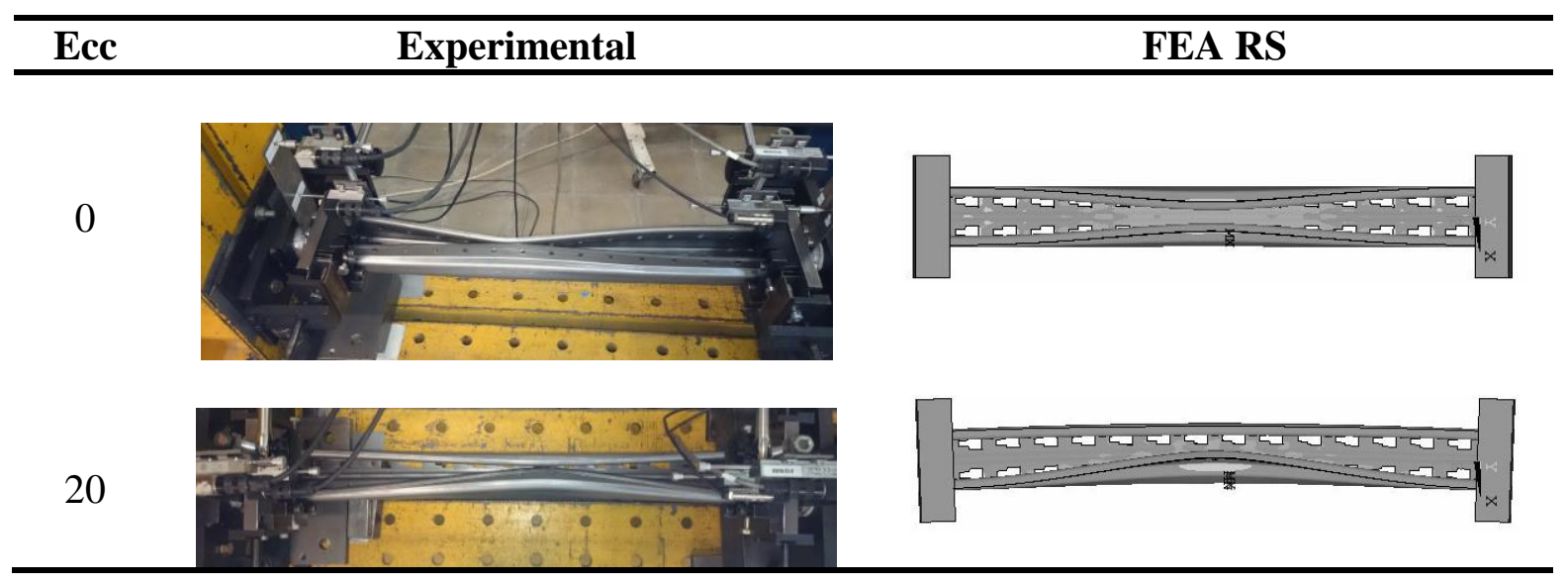

Figure 16: Failure modes obtained from experimental tests and FEA with residual stresses and strain hardening for an eccentricity of $0 \mathrm{~mm}$ and $20 \mathrm{~mm}$, respectively.

Table 4: Ultimate loads obtained by introducing a symmetric distortional (SD) or anti-symmetric distortional (AD) geometric imperfection on the analysis.

\begin{tabular}{c|cc|cc}
\hline & \multicolumn{2}{|c|}{ FEA GI ultimate loads (N) } & \multicolumn{2}{c}{ FEA/EXP } \\
Eccentricity (mm) & SD & AD & SD & AD \\
\hline 0 & 115283 & 122658 & 0.98 & 1.04 \\
5 & 103827 & 103374 & 1.02 & 1.01 \\
10 & 89360 & 89280 & 1.00 & 1.00 \\
15 & 79113 & 78431 & 1.03 & 1.02 \\
20 & 70556 & 70404 & 0.98 & 0.98 \\
\hline \hline \multicolumn{3}{c}{ Mean } & 1.00 & 1.01 \\
\multicolumn{4}{c}{ St } \\
\hline
\end{tabular}

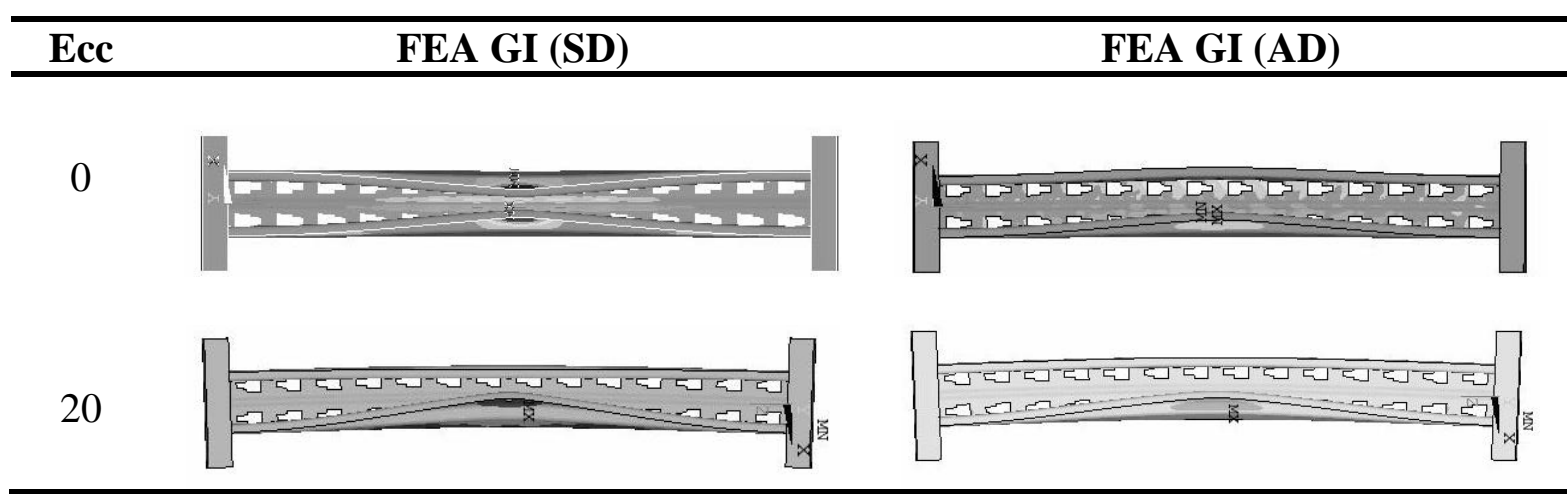

Figure 17: Comparison of the numerical failure modes obtained with a symmetric distortional (SD) and anti-symmetric distortional (AD) geometric imperfection on the analysis 


\subsection{Analysis of the compression load - axial displacement curve}

Through the force and displacement transducers the experimental compression load - axial displacement curve (F-d) is calculated for each sample. Figure 18 shows the experimental relationship obtained for uprights with $10 \mathrm{~mm}$ and $20 \mathrm{~mm}$ of eccentricity. In order to compare the numerical and experimental curves, the deformation of the frame where the tests are done has to be taken into account.

The numerical and experimental curves are compared in Figure 18. The results show that FEA with residual stresses has a smoother behaviour near to the maximum value. Moreover, the post-collapse behaviour is stiffer if the residual stresses and the strength enhancement of corner areas are taken into account. Consequently, the curves obtained with these analyses are more similar to the experimental ones.

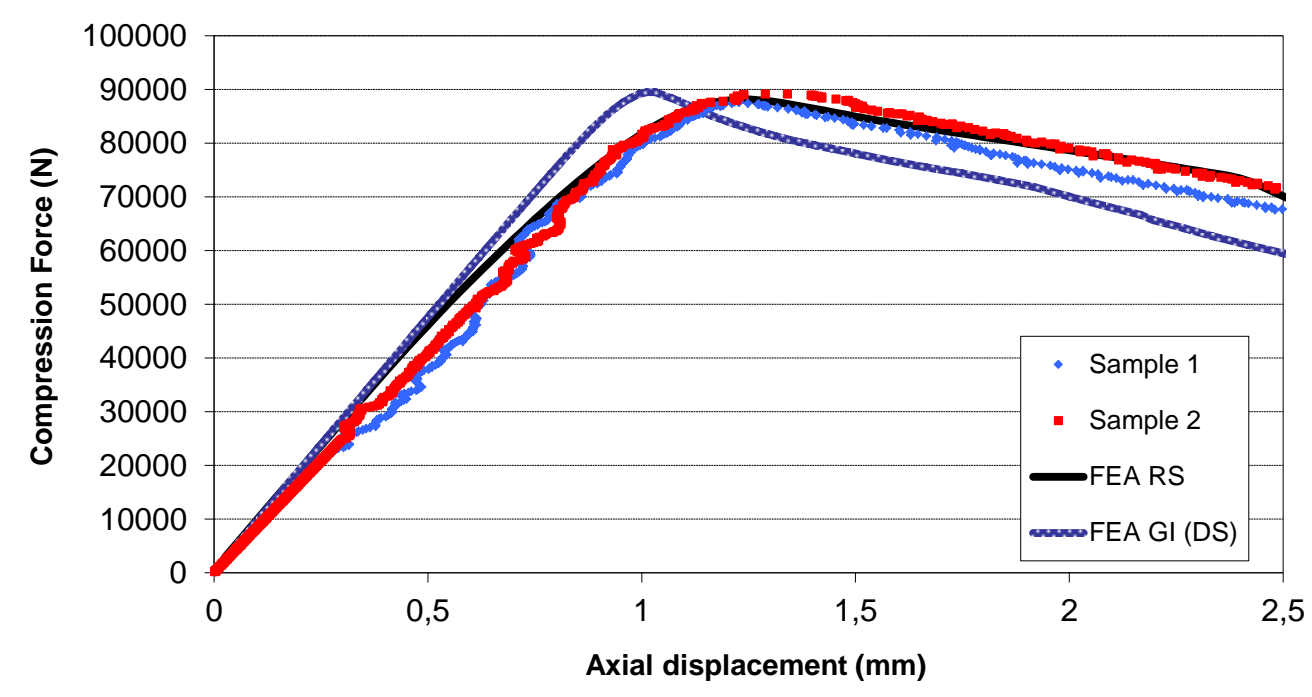

(a)

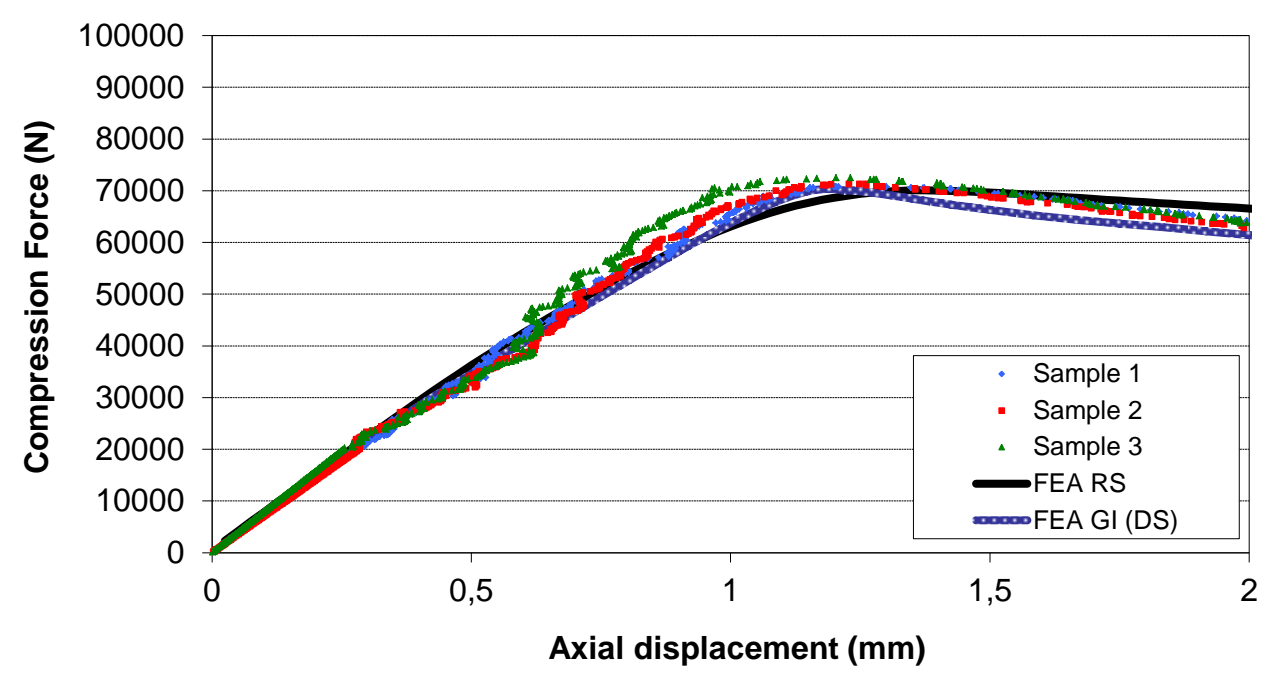

(b)

Figure 18: Comparison of Experimental and FEA curves for an eccentricity of $10 \mathrm{~mm}$ (a) and $20 \mathrm{~mm}$ (b), respectively. 


\section{CALCULATION ACCORDING TO EUROPEAN STANDARDS}

The ultimate load of all cases have also been calculated through the European Standards EN 1993-1-3: Eurocode 3 [17] and EN 15512 [18] and the results obtained have been compared to experimental test and numerical analysis. Moreover, this analytical method provides a simple manner to obtain the influence of the bending moment on the load carrying capacity of the rack column in function of the applied eccentricity.

One of the difficulties to apply the European Standards to pallet rack columns is how to handle the perforations influence and the distortional buckling influence. It is well known that these effects can be taken into account by using effective properties, such as an effective area $\left(\mathrm{A}_{\mathrm{eff}}\right)$ and section modulus $\left(\mathrm{W}_{\mathrm{eff}}\right)$.

The EN 1993-1-3 proposes an analytical method (Eq 1) to obtain a reduction factor for the distortional buckling $\left(\chi_{\mathrm{d}}\right)$, used to obtain the distortional effective area $\left(\mathrm{A}_{\mathrm{eff}, \mathrm{d}}\right)$.

$$
\begin{aligned}
& \overline{\lambda_{d}}=\sqrt{\frac{f_{y}}{\sigma_{c r, s}}} \\
& \chi_{d}=1 \longrightarrow \overline{\lambda_{d}} \leq 0,65 \\
& \chi_{d}=1,47-0,723 \overline{\lambda_{d}} \longrightarrow 0,65 \overline{<\lambda_{d}}<1,38 \\
& \chi_{d}=\frac{0,66}{\overline{\lambda_{d}}} \longrightarrow \overline{\lambda_{d}} \geq 1,38 \\
& A_{e f f, d}=\chi_{d} \cdot A
\end{aligned}
$$

In order to apply Eq 1, the elastic critical stress for a pure symmetric distortional mode is calculated by a Generalised Beam Theory linear buckling analysis done in MATLAB. This analysis takes into account the influence of the perforations by using an equivalent thickness for the distortional mode $\left(\mathrm{t}_{\mathrm{eq}}, \mathrm{Eq} 2\right)$ on the web zone where the perforation is located. The mode used is based on [19] (Figure 19).

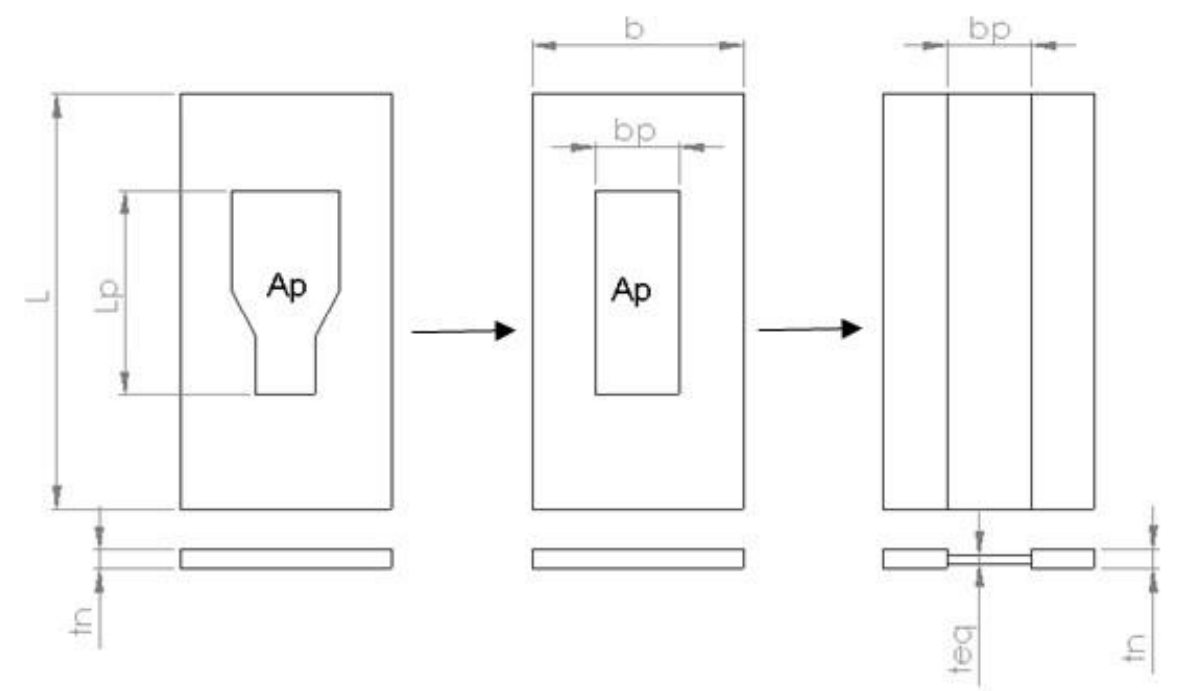

Figure 19: Scheme that shows the mains parameters involved on the equivalent thickness calculation. (Ap corresponds to the area of the web's perforations). 
$t_{e q}=0,9 \cdot t_{n}\left(\frac{L-L_{p}}{L}\right)^{\frac{1}{3}}$

After that, Equation 3 validates the load case of a rack column under compression and bending load provided by the EN15512 (part 9.7.6.4) is used.

$$
\frac{N}{\chi_{\min } \cdot A_{e f f, d} \cdot f_{y}}+\frac{K_{L T} \cdot M_{y}}{\chi_{L T} \cdot W_{e f f, y} \cdot f_{y}} \leq 1
$$

Where the parameter $\mathrm{K}_{\mathrm{LT}}$ can be obtained by $\mathrm{Eq}$ (4)

$$
K_{L T}=1-\frac{\mu_{L T} \cdot N}{\chi_{y} \cdot A_{e f f} \cdot f_{y}}
$$

For the determination of $\mathrm{K}_{\mathrm{LT}}$ parameter, the distortional effective area $\left(\mathrm{A}_{\mathrm{eff}, \mathrm{d}}\right)$ have been used instead of the local effective area obtained through the experimental stub column test due to its smaller value.

In these analyses, the bending moment is applied by means of axial forces eccentrically applied, therefore, Eq 4 can be written to obtain the maximum axial load that the rack column can carry out (Eq 5).

$$
\frac{N}{\chi_{\min } \cdot A_{e f f, d} \cdot f_{y}}+\frac{\left(1-\frac{\mu_{L T} \cdot N}{\chi_{y} \cdot A_{e f f, d} \cdot f_{y}}\right) \cdot e_{c c} \cdot N}{\chi_{L T} \cdot W_{e f f, y} \cdot f_{y}}=1
$$

Where $e_{c c}$ is the applied eccentricity during the experimental test.

Table 5 and Figure 20 shows the results of the maximum axial load obtained by the analytical model provided by the European Standards. It can be observed that the analytical model provides a good agreement with the experimental test in spite of the difficulties to handle the perforations effect and the distortional influence on the load carrying capacity of the upright.

Moreover, the contribution of the each effort on the load carrying capacity of the rack upright has been obtained though Eq 5, where the first term correspond to the axial load and the second to the bending moment. Table 6 shows that the maximum applied eccentricity produces a contribution of the bending moment around $38 \%$, a contribution that could be found in a typical pallet rack structure. 
Table 5 - Comparison of the experimental and analytical (EN15512) maximum axial load

\begin{tabular}{|c|c|c|c|}
\hline & \multicolumn{2}{|c|}{ Axial Load (N) } & Ratio \\
\hline $\begin{array}{c}\text { Eccentricity } \\
(\mathbf{m m})\end{array}$ & EN15512 & $\operatorname{Exp}($ mean) & EN/EXP \\
\hline 0 & 113372 & 117590 & 0.96 \\
\hline 5 & 97952 & 102257 & 0.96 \\
\hline 10 & 86360 & 89493 & 0.96 \\
\hline 15 & 77297 & 76743 & 1.01 \\
\hline 20 & 69999 & 71673 & 0.98 \\
\hline & & mean & 0.97 \\
\hline & & st & 0.02 \\
\hline
\end{tabular}

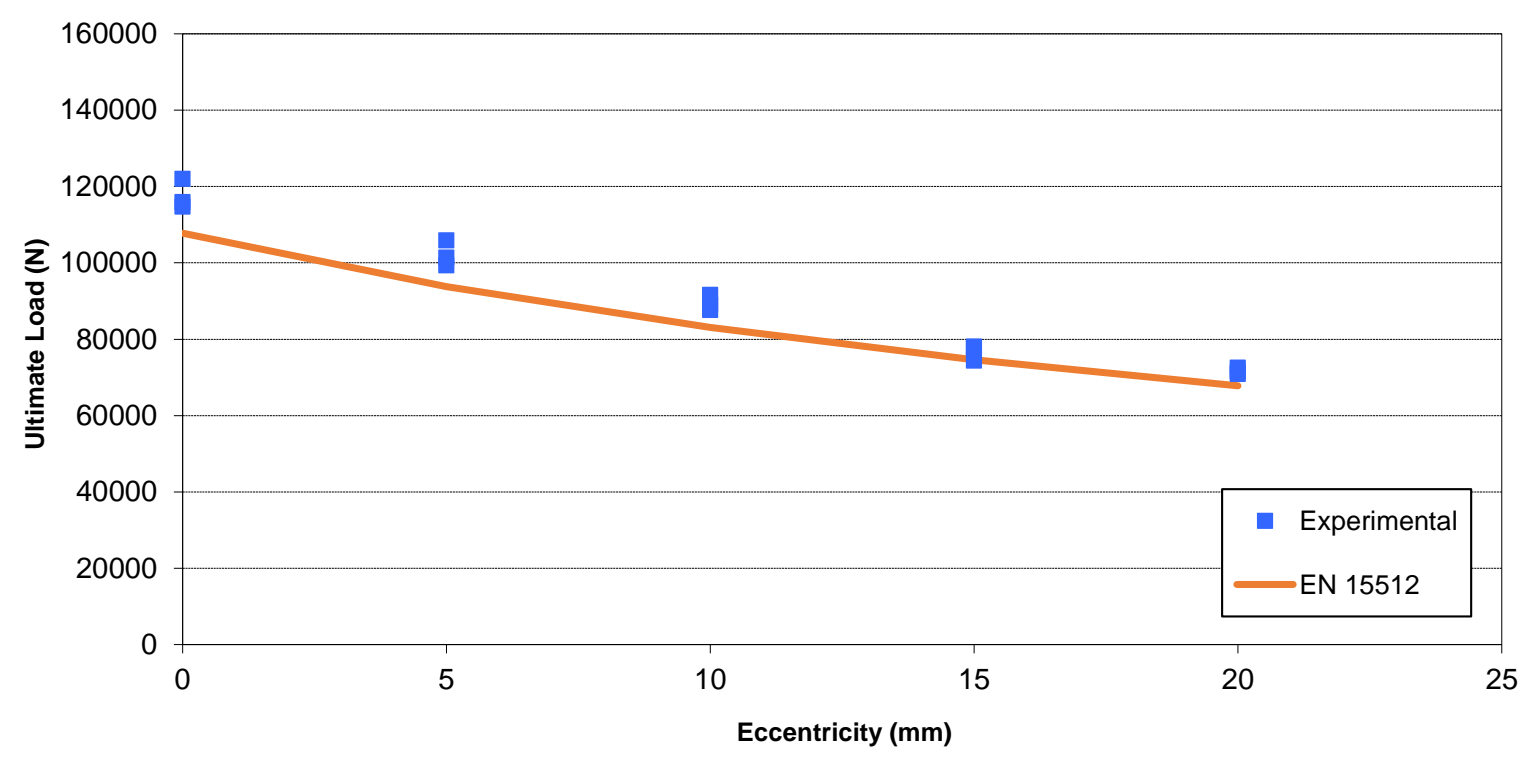

Figure 20 - Comparison of the experimental and analytical (EN 15512) loads

Table 6 - Contribution of each effort on the load carrying capacity provided by Eq 5

\begin{tabular}{c|c|c|c}
\hline Eccentricity $(\mathbf{m m})$ & Axial Load (N) & Axial contribution(\%) & Bending Contribution(\%) \\
\hline 0 & 113372 & 100 & 0 \\
5 & 97947 & 86 & 14 \\
10 & 86353 & 76 & 24 \\
15 & 77288 & 68 & 32 \\
20 & 69989 & 62 & 38
\end{tabular}




\section{CONCLUSIONS}

A study of the structural behaviour of a rack upright subjected to combined compression and bending load has been presented. Two different methodologies have been analysed in order to determinate the load carrying capacity through the finite element method. The results obtained have been validated by experimental values.

First of all, the experimental tests show the influence of the bending moment induced by an axial force eccentrically applied on the load carrying capacity of the upright can be very relevant. Therefore, it is essential that finite element analysis reproduce this influence in order to obtain accurate predictions. Two different FEA methodologies have been described to correctly simulate this load cases.

The first methodology presented does not take into account the residual stresses and the strength enhancement due to the manufacturing process. The results show that an initial geometrical imperfection has to be included into the nonlinear analysis for all eccentricities to obtain accurate results if a distortional column length is analysed. Moreover, the shape of this initial geometrical perturbation is only relevant to obtain accurate results if the failure mode obtained is different to the experimental one.

The residual stresses and the strength enhancement of corner areas has been included in the second methodology developed. Good predictions of the ultimate loads are also obtained for all eccentricities. The main advantage of this second methodology is the lack of necessity to introduce an arbitrary geometrical imperfection as initial state to obtain accurate results.

The residual stresses and the strain hardening have influence on the F-d curve. The postbuckling behaviour of the rack member is stiffer and the F-d curve has a smoother relationship near the maximum value.

To sum up, the analytical model provided by the European Standards shows a good agreement with experimental test in spite of the difficulties to handle out the influence of perforations and distortional buckling.

\section{REFERENCES}

[1] Bernuzzi C., Gobetti A., Gabbianelli G., Simoncelli M., "Unbraced pallet rack design in accordance with European practice-Part2: Essential verification checks", Thin-Walled Struct, 86, 208-229, 2015.

[2] Roure F., Pastor M.M., Casafont M., Somalo M.R., "Stub column tests for racking design: Experimental testing, FE analysis and EC3", Thin-Walled Struct, 49, 167-184, 2011.

[3] Casafont M., Pastor M.M., Roure F., Pekoz T., "An experimental investigation of distortional buckling of steel storage rack columns", Thin-Walled Struct, 49, 933-946, 2011.

[4] Miller T.H. and Pekoz T., "Load-Eccentricity Effects on Cold-Formed Steel Lipped-Channel Columns", J Struct Eng, 120(3), 805-823, 1994.

[5] Zhang Y., Wang C., Zhang Z., "Tests and finite element analysis of pin-ended channel columns with inclined simple edge stiffeners", J Constr Steel Res, 63(3), 383-395, 2007.

[6] Mohri F., Bouzerira C., Potier-Ferry M., "Lateral buckling of thin-walled beam-column elements under combined axial and bending loads", Thin-Walled Struct, 46(3), 290-302, 2008.

[7] Torabian S., Zheng B., Schafer B.W., "Experimental response of cold-formed steel lipped channel beam-columns", Thin-Walled Struct, 86, 225-241, 2015.

[8] Davies J.M., Leach P., Tylor A., "The Design of Perforated Cold-Formed Steel Sections Subject to Axial Load and Bending", Thin-Walled Struct, 29(1-4), 141-157, 1997. 
[9] Crisan A., Ungureanu V., Dubina D., "Influence of web members on the in-plane and out-ofplane capacities steel storage upright frames", Thin-Walled Struct, 81, 175-184, 2014.

[10] EN15512:2009: Steel static storage systems - Adjustable pallet racking systems - Principles for structural design, CEN, Brussels; 2009.

[11] Bernuzzi C. and Simoncelli M., "European design approaches for isolated cold-formed thinwalled beam-columns with mono-symmetric cross-section", Eng Struct, 89, 152-168, 2015.

[12] ANSYS Mechanical APDL 15.0.

[13] Pastor M.M., Casafont M., Bonada J., Roure F., "Imperfection amplitudes for nonlinear analysis of open thin-walled steel cross-sections used in rack column uprights", Thin-Walled Struct, 76, 28-41, 2014.

[14] Pastor M.M., Bonada J., Roure F., Casafont M., "Residual stresses and initial imperfections in non-linear analysis", Eng Struct, 46, 493-507, 2013.

[15] Bonada J., Pastor M.M., Roure F., Casafont M., "Influence of the cold work effects in perforated rack columns under pure compression load", Eng Struct, 97, 130-139, 2015.

[16] Bonada J., Casafont M., Roure F., Pastor M.M., "Selection of the initial geometrical imperfection in nonlinear FE analysis of cold-formed steel rack columns", Thin-Walled Struct, 51, 99-111, 2012.

[17] EN 1993-1-3. Eurocode 3 - Design of steel structures - Part 1-3: General rules - Supplementary rules far cold-formed members and sheeting. September 2005.

[18] EN 15512. Steel static storage systems - Adjustable pallet racking system - Principles for structural design. European Standard. European Committee for Standardization. March 2009.

[19] Casafot M., Pastor M., Bonada J., Roure F., Peköz T. "Linear buckling analysis of perforated steel storage rack columns with the Finite Strip Method", Thin-Walled Struct, 61, 71-85, 2012. 